\title{
The Problem of Transitivity of Part-Whole Relations in Conceptual Modeling Revisited
}

\author{
Giancarlo Guizzardi \\ Ontology and Conceptual Modeling Research Group (NEMO) \\ Computer Science Department, \\ Federal University of Espírito Santo (UFES), Brazil \\ gguizzardi@inf.ufes.br
}

\begin{abstract}
Parthood is a relation of fundamental importance in a number of disciplines including cognitive science, linguistics and conceptual modeling. However, one classical problem for conceptual modeling theories of parthood is deciding on the transitivity of these relations. This issue is of great importance since transitivity plays a fundamental role both conceptually (e.g., to afford inferences in problem-solving) and computationally (e.g., to afford propagations of properties and events in a transitive chain). In this article we address this problem by presenting a solution to the case of part-whole relations between functional complexes, which are the most common types of entities represented in conceptual models. This solution comes in two parts. Firstly, we present a formal theory founded on results from formal ontology and linguistics. Secondly, we use this theory to provide a number of visual patterns that can be used to isolate scopes of transitivity in part-whole relations represented in diagrams.
\end{abstract}

\section{Introduction}

Parthood is a relation of fundamental importance from the cognitive and linguistic perspectives [1,2]. In conceptual modeling, part-whole relations have also been considered of substantial significance. It is present in practically all conceptual/objectoriented modeling languages (e.g., OML, UML, EER) and, although it has not yet been adopted as a modeling primitive in the semantic web languages, many authors have already pointed out its relevance for reasoning in description logics (e.g., [3]).

Theories of parts have been a central point of interest in philosophical enquiry since the pre-socratic philosophers and along the years many precise formal theories have been developed (e.g., General Extensional Mereology, Calculus of Individuals) [4]. These formal theories provide an important starting point for the understanding and axiomatization of the notion of Part. Nonetheless, despite their importance, there are many controversial properties that they ascribed to the part-whole relation that cannot be accepted by cognitive and conceptual theories of parthood $[2,4,5]$. One of these controversial properties is the unrestricted transitivity of parthood.

In philosophical ontology, all mereological theories include transitivity as an axiom for the formal part-whole relation. Also in many conceptual modeling languages, the part-whole relations are considered to be transitive (e.g., composition relation in UML). However, there are many counter-examples in the literature of part-whole 
relations in which transitivity is not warranted by language or cognition. For instance: (i) Rio de Janeiro is part of Brazil and Brazil is part of the United Nations (UN), it is not the case that Rio de Janeiro is part of the UN; (ii) the heart is part of the musician, the musician is part of the orchestra, but the heart is not part of the orchestra $[2,4]$.

In [4], we revised the classical typology of parthood relations proposed in [1]. As demonstrated there, the six linguistically-motivated types of part-whole relation proposed by [1] give rise to only four distinct ontological types, namely: (a) subquantityquantify (e.g., alcohol-wine) - modeling parts of an amount of matter which are unified in a whole due to a topological connection relation; (b) member-collective (e.g., a specific tree - the black forest) - modeling a collective entity in which all parts play an equal role w.r.t. the whole; (c) subcollective-collective (e.g., the north part of the black forest- the black forest); (d) component - functional complex (e.g., heartcirculatory system, engine - car) - modeling an entity in which all parts play a different role w.r.t. the whole, thus, contributing to the functionality of the latter. Moreover, in [4], we have demonstrated that there is a strong connection between the issue of transitivity of parthood and the type of the relation being considered. For instance, it can be formally proved that subquantity-quantify and subcollective-collective are always transitive. Moreover, although member-collective is never transitive, a combination of member-collective and subcollective-collective is again always transitive.

Despite their relevance, these results do not suffice as a general solution for the problem of transitivity in conceptual modeling, since most of the entities which are represented in conceptual models are actually functional complexes (e.g., Persons, Cars, Computers, Cells, Organs, Organizations, Organizational Units). Parthood relations between functional complexes are neither transitive nor intransitive, but nontransitive, i.e., transitive in certain occasions and intransitive in others [6]. For this reason, the current attempts to provide real-world semantics for part-whole relations in the conceptual modeling literature simply exclude transitivity from the list of primary properties of part-whole relations [7]. This solution is, again, non-satisfactory. From both a conceptual and computational point of view, there are many benefits from explicitly reasoning with the transitivity of parthood. Examples include propagation of properties and events along the transitive chain of parts (e.g., spatial change, rotation, creation, destruction) and diagnostic reasoning with transitive parts in biomedical conceptual models. For this reason it is fundamental to understand why transitivity holds in some cases and not in others, and to determine the contexts in which part-whole relations are guaranteed to be transitive.

The contributions of this article are two-fold. Firstly, we build on a formal ontological analysis of relations [8] and on the pioneering theory of transitivity of linguistic functional parthood relations [2] to propose a formal theory and typology of partwhole relations between functional complexes. Secondly, we employ this theory to propose a number of visual patterns that can be used as a methodological support for the identification of contexts of transitivity for this mostly common type of partwhole relations in conceptual modeling.

The remainder of this article is organized as follows. Section 2 briefly discusses an ontological analysis of relations based on a Foundational Ontology. Section 3 employs this analysis to interpret the specific case of part-whole relations in functional complexes. Section 4 uses the results of section 3 to propose a typology of functional 
part-whole relations and a number of visual patterns for isolating the context of transitivity in conceptual models. Finally, section 5 elaborates on some final consideration.

\section{Background: An Ontological Analysis of Relations}

In [8], we have presented an in depth analysis of domain relations from an ontological point of view. In particular, we have employed the Unified Foundational Ontology (UFO), a formal framework which has been constructed by considering a number of theories from formal ontology in philosophy, but also cognitive science, linguistics and philosophical logics. In a number of papers, UFO has been successfully employed to analyze and provide real-world semantics for conceptual modeling grammars and specifications. Here, we make a very brief presentation of this foundational ontology and concentrate only on the categories which are germane to the purposes of this article. For an in depth discussion on the categories of UFO, empirical evidence for the choice of its categories as well as formal categorization, one should see [4].

A fundamental distinction in this ontology is between the categories of Objects and Tropes. Objects are existentially independent entities. Examples include ordinary objects of everyday experience such as an individual person, an organization, an organ, a car, and The Rolling Stones ${ }^{1}$. The word Trope, in contrast, denotes, what is sometimes named an individualized (objectified) property, a moment, an accident, or property in particular. A trope is an individual that can only exist in other individuals. Typical examples of tropes are a color, a connection, an electric charge, a symptom, a covalent bond. Tropes have in common that they are all dependent of other individuals (their bearers), i.e., an important feature that characterizes all tropes is that they can only exist in other individuals (in the way in which, for example, electrical charge can exist only in some conductor, or that a covalent bond can only exist if those connecting atoms exist). To put it more technically, we say that they inhere on other individuals. Inherence (symbolized as $i$ ) is a formal relation that has the following metaproperties: (a) irreflexivity; (b) asymmetry; (c) intransitivity; (d) exclusive existential dependence, i.e., if $\mathrm{x}$ inheres in $\mathrm{y}$ then $\mathrm{x}$ cannot exist in a given situation without that very specific y existing in that same situation (existential dependence) and there is no $\mathrm{z}$ different from $\mathrm{y}$ such that $\mathrm{x}$ inheres in $\mathrm{z}$. Finally, existential dependence can also be used to differentiate intrinsic tropes and Relators (relational tropes): intrinsic tropes are dependent of one single individual (e.g., color, a headache, a temperature); relators depend on a plurality of individuals (e.g., an employment, a marriage).

Another important distinction in the UFO ontology is within the categories of relations. Following the philosophical literature, it recognizes two broad categories of relations, namely, material and formal relations [8]. Formal relations hold between two or more entities directly, without any further intervening individual. Examples include the relations of existential dependence (ed), Subtype, instantiation (::), formal parthood $(<)$, inherence $(i)$, among many others not discussed here [4]. Domain relations such as working at, being enrolled at, and being the husband of are of a completely different nature. These relations, exemplifying the category of Material relations,

${ }^{1}$ According to this definition, the category of objects can include quantities, collectives and functional complexes. However, all objects we consider in this article are examples of functional complexes. 
have material structure of their own. Whilst a formal relation such as the one between Paul and his headache $x$ holds directly and as soon as Paul and $x$ exist, for a material relation of being treated in between Paul and the medical unit $\mathrm{MU}_{1}$ to exist, another entity must exist which mediates Paul and $\mathrm{MU}_{1}$. These entities are termed relators.

Relators are individuals with the power of connecting entities. For example, a medical treatment connects a patient with a medical unit; an enrollment connects a student with an educational institution; a covalent bond connects two atoms. The notion of relator is supported by several works in the philosophical literature [9] and, they play an important role in answering questions of the sort: what does it mean to say that John is married to Mary? Why is it true to say that Bill works for Company X but not for Company Y? Again, relators are special types of tropes which, therefore, are existential dependent entities. The relation of mediation (symbolized $m$ ) between a relator $r$ and the entities $r$ connects is a sort of (non-exclusive) inherence and, hence, a special type of existential dependence relation. It is formally required that a relator mediates at least two distinct individuals [4].

An important notion for the characterization of relators (and, hence, for the characterization of material relations) is the notion of foundation. Foundation can be seen as a type of historical dependence [10], in the way that, for instance, an instance of being kissed is founded on an individual kiss, or an instance of being punched by is founded on an individual punch, an instance of being connected to between airports is founded on a particular flight connection. Suppose that John is married to Mary. In this case, we can assume that there is an individual relator $\mathrm{m}_{1}$ of type marriage that mediates John and Mary. The foundation of this relator can be, for instance, a wedding event or the signing of a social contract between the involved parties. In other words, for instance, a certain event $e_{1}$ in which John and Mary participate can create an individual marriage $\mathrm{m}_{1}$ which existentially depends on John and Mary and which mediates them. The event $\mathrm{e}_{1}$ in this case is the foundation of relator $\mathrm{m}_{1}$.

Now, let us elaborate on the nature of the relator $\mathrm{m}_{1}$. There are many intrinsic tropes that John acquires by virtue of being married to Mary. For example, imagine all the legal responsibilities that John has in the context of this relation. These newly acquired properties are intrinsic tropes of John which, therefore, are existentially dependent on him. However, these tropes also depend on the existence of Mary. We name this type of trope externally dependent tropes, i.e., externally dependent tropes are intrinsic tropes that inhere in a single individual but are existentially dependent on (possibly multiple) other individuals. The individual which is the aggregation of all externally dependent tropes that John acquires by virtue of being married to Mary is named a qua individual (in this case, John-qua-husband-of-Mary). A qua individual is, thus, defined as an individual composed of all externally dependent tropes that inhere in the same individual and share the same foundation. In the same manner, by virtue of being married to John, Mary bears an individual Mary-qua-wife-of-John.

The notion of qua individuals is the ontological counterpart of what has been named role instance in the literature [11] and represent the properties that characterize a particular mode of participation of an individual in a relation. Now, the entity which is the sum of all qua individuals that share the same foundation is a relator. In this example, the relator $\mathrm{m}_{1}$ which is the aggregation of all properties that John and Mary acquire by virtue of being married to each other is an instance of the relational property marriage. 
The relator $\mathrm{m}_{1}$ in this case is said to be the truthmaker of propositions such as "John is married to Mary", "Mary is married to John", "John is the husband of Mary", and "Mary is the wife of John". In other words, material relations such as being married to, being legally bound to, being the husband of can be said to hold for the individuals John and Mary because and only because there is an individual relator marriage $m_{1}$ mediating the two. Thus, as demonstrated in [8], material relations are purely linguistic/logical constructions which are founded on and can be completely derived from the existence of relators. In fact, in [8], we have defined a formal relation of derivation (symbolized as der) between a relator type (e.g., Marriage) and each material relation which is derived from it.

Finally, there is an intimate connection between qua individuals and role types: let $\mathrm{T}$ be a natural type (kind) instantiated by an individual $\mathrm{x}$, and let $\mathrm{R}$ be a role type specializing $\mathrm{T}$. We have that there is a qua individual type $\mathrm{Q}$ such that $\mathrm{x}$ instantiates $\mathrm{R}$ iff $\mathrm{x}$ bears an instance of $\mathrm{Q}$. Alternatively, we have that for every role type $\mathrm{R}$ there is a relator type $\mathrm{RR}$ such that $\mathrm{x}$ instantiates $\mathrm{R}$ iff $\mathrm{x}$ is mediated by an instance of RR. Note that this conforms to the formal property of roles as relationally dependent types [12].

The summary of the discussion promoted in this section is illustrated in figures 1ac. Figure 1.a, illustrates the inherence relation between John and his externally dependent tropes which are existentially dependent on Mary (as well as analogous relations in the converse direction). In figure 1.b, John instantiates the role type Husband (which is a specialization of the natural type (Male) Person) iff there is a qua individual John-qua-husband-of-Mary which inheres in John. Moreover, this figure illustrates that the qua individuals John-qua-husband-of-mary and Mary-qua-wife-ofJohn are mutually existentially dependent. In other words, John cannot be the Husband of Mary without Mary being the wife of John [4]. Finally, figure 1.c shows that the material relation married to is derived from the relator type Marriage and, thus, tuples such as $<$ John,Mary $>$ and $<$ John,Mary $>$ are instances of this relation iff there is an instance of Marriage that mediates the elements of the tuple.

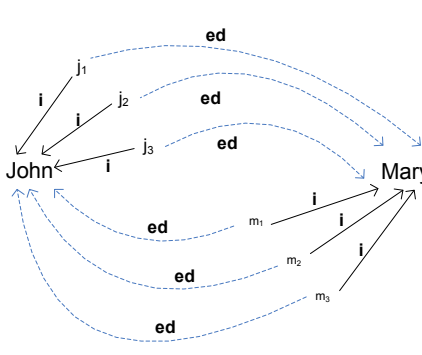

(a)

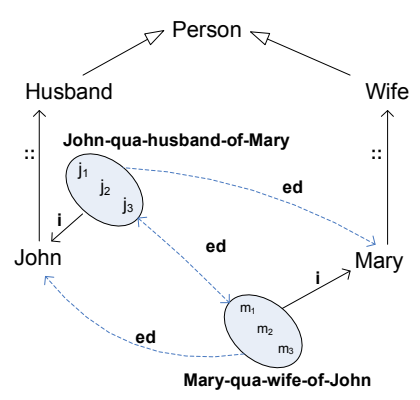

(b)

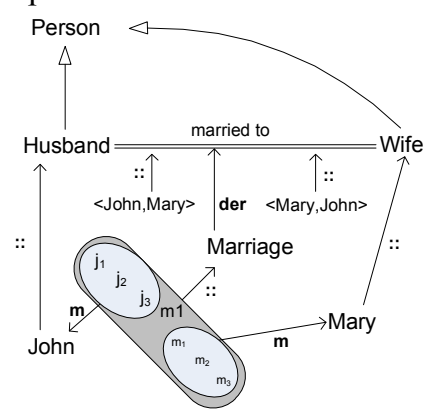

(c)

Fig.1. (a-left) Objects and their inhering externally dependent tropes. (b-center) Objects, their instantiating roles and their inhering qua individuals. (c) Material Relations are founded on relators that mediate their relata.

Notice that the relation between the two qua individuals and the relator $\mathrm{m}_{1}$ is an example of formal relation of parthood [8]. As previously discussed, formal parthood conforms to the meta-properties prescribed by mereology and, therefore, is always transitive. Another example of a parthood relation that conform to axioms of mere- 
ology is the spatial (temporal) part-whole relation between regions of space (or time) [9]. One of the major points advocated in this article is that the domain part-whole relations that interest us in conceptual modeling are not formal but material relations: the fact that Brazil is part of the United Nations or that Paul's transplanted heart is part of his body demand for the existence of founding events and consequent relators.

\section{Functional Complexes and Functional Dependence}

As we previously discussed, the parts of a functional complex have in common the fact that they all posses a functional link with the complex. In other words, they all contribute to the functionality (or the behavior) of the complex. According to [2], parthood relations between complexes represent, aside from the mereological relation itself, relations of functional dependence. Take the example of figure 2. Following [2], we claim that this type of relationship represented between the types Heart and Body is what is termed Generic Functional Dependence between two types. This relationship can be defined as follows: (1) GFD(X,Y) $\equiv \forall \mathrm{x}(\mathrm{x}:: \mathrm{X}) \wedge \mathrm{F}(\mathrm{x}, \mathrm{X}) \rightarrow \exists \mathrm{y} \neg(\mathrm{y}=$ $\mathrm{x}) \wedge(\mathrm{y}:: \mathrm{Y}) \wedge \mathrm{F}(\mathrm{y}, \mathrm{Y})$.

$$
\begin{array}{|lll|}
\hline \text { Heart } & 1 & 1 \\
& &
\end{array}
$$

Fig.2.A parthood relation between two Functional Complex Types

The predicate $\mathrm{F}(\mathrm{x}, \mathrm{X})$ in formula (1) has the meaning $\mathrm{x}$ functions as an $\mathrm{X}$. In Vieu and Aurnague's theory [2], it is not necessary for an $\mathrm{X}$ that it functions as an $\mathrm{X}$. So for instance, it is not the case that in every circumstance an engine functions as an engine. We thus can think of a type $\mathrm{X}^{\mathrm{F}}$ which is a specialization of $\mathrm{X}$ according to the specialization condition expressed by the predicate $\mathrm{F}(\mathrm{x}, \mathrm{X})$, so that every $\mathrm{X}^{\mathrm{F}}$ is a $\mathrm{X}$ functioning as a $\mathrm{X}$. We name the type $\mathrm{X}^{\mathrm{F}}$ a functional restriction of $\mathrm{X}$. Notice that $\mathrm{X}^{\mathrm{F}}$ in this case is a type which can be characterized by the qua individual $\mathrm{q}_{\mathrm{X}}$. This qua individual, in turn, stands for the tropes bearing in an X's while functioning as such, or the particular behaviour of an $\mathrm{X}$ while functioning as an $\mathrm{X}$. For instance, an engine $\mathrm{x}$ can have the property of emitting a certain number of decibels or being able to perform certain tasks only when functioning as an engine.

In figure 3.a, we can create specializations of the types Heart and Body to the types Heart ${ }^{\mathrm{F}}$ (FunctioningHeart) and Body ${ }^{\mathrm{F}}$ (FunctioningBody). In this picture, the arrow with the hollow head represents subtyping. The symbols ::, $i$ and $e d$ represent instantiation, inherence and existential dependence, respectively. Whenever a heart functions as such, i.e., whenever it instantiates the type FunctioningHeart, there is a qua individual $\mathrm{q}_{\mathrm{h}}$ that inheres in it. Mutatis Mutandis, the same goes to Body and FunctioningBody in this picture. As represented in this picture, the qua individuals $\mathrm{q}_{\mathrm{h}}$ and $\mathrm{q}_{\mathrm{b}}$ are existentially dependent on each other. In this case, ed $\left(\mathrm{q}_{\mathrm{h}}, \mathrm{q}_{\mathrm{b}}\right)$ can be interpreted as "the heart functioning behavior existentially depends on the body functioning behavior". In this model the converse also holds, i.e., that ed $\left(\mathrm{q}_{\mathrm{b}}, \mathrm{q}_{\mathrm{h}}\right)$, or that "the body functioning behaviour existentially depends on the heart functioning behavior". Additionally, according to our model, a heart functioning $\mathrm{q}_{\mathrm{h}}$ must inhere in a heart $\mathrm{h}$. Likewise, a body functioning $\mathrm{q}_{\mathrm{b}}$ must inhere a body $\mathrm{b}$. From this we have that when- 
ever a heart $\mathrm{h}$ functions as a heart (i.e., $\left.i\left(\mathrm{q}_{\mathrm{h}}, \mathrm{h}\right)\right)$ there must exist a body functioning behavior $\mathrm{q}_{\mathrm{b}}\left(\right.$ from ed $\left.\left(\mathrm{q}_{\mathrm{h}}, \mathrm{q}_{\mathrm{b}}\right)\right)$, which in turn, inheres a body $\mathrm{b}$ (i.e., $\left.i\left(\mathrm{q}_{\mathrm{b}}, \mathrm{b}\right)\right)$. In other words, whenever a heart $\mathrm{h}$ functions as a heart, there must be $\mathrm{a}$ body $\mathrm{b}$ functioning as a body. Again, from the model of figure 3.a we can derive the converse information, namely, that whenever a body $\mathrm{b}$ functions as a body, there must be a heart $\mathrm{h}$ functioning as a heart.
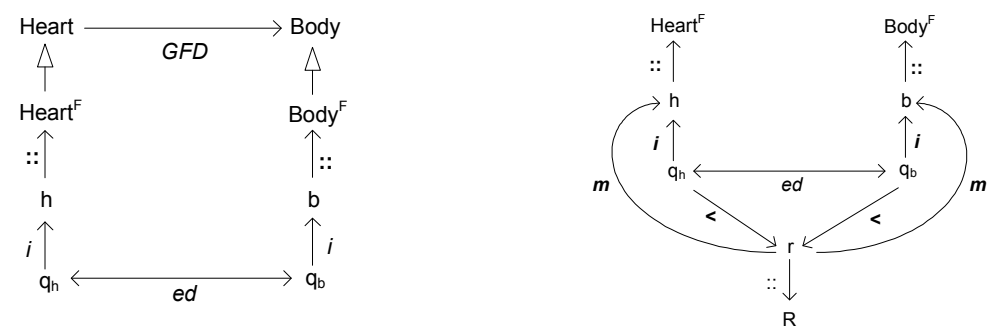

Fig.3.(a-left) Representation of Types with Generic Functional Dependence and their Functional Restrictions. (b) Representation of the relator instance composed of two functional qua individuals.

By definition of the relational qua individuals, $\mathrm{q}_{\mathrm{h}}$ and $\mathrm{q}_{\mathrm{b}}$ in figure 3.a are externally dependent tropes that compose a relator $r$ that, in turn, can be said to mediate the instances of FunctioningHeart and FunctioningBody. This idea is depicted in figure 3.b. The symbols $\mathrm{m}$ and $<$ in this picture represent the mediation relation and the formal proper parthood relation, respectively.

The relator universal $\mathrm{R}$ of which the relator $\mathrm{r}$ in figure 3.b is an instance, can be said to derive the material relation $\varphi_{R}$ between the universals FunctioningHeart and FunctioningBody. We shall define here the more general binary predicate $\varphi(x, y) \equiv \exists r$ $\mathrm{m}(\mathrm{r}, \mathrm{x}) \wedge \mathrm{m}(\mathrm{r}, \mathrm{y})$. In other words, $\varphi(\mathrm{x}, \mathrm{y})$ holds iff there is a relator $\mathrm{r}$ which mediates these two individuals. More naturally, in this case, we can say that $\varphi$ hold of $x$ and $y$ of type $\mathrm{X}$ and $\mathrm{Y}$ iff $\mathrm{x}$ to function as an $\mathrm{X}$ is depends on $\mathrm{y}$ functioning as a $\mathrm{Y}$, and viceversa. Notice that the functional restriction FunctioningHeart (FunctioningBody) is indeed relationally dependent and, consequently, it conforms to the characterization of role types previously discussed: a FunctioningHeart is a Heart functioning as a Heart in relation to a Body functioning as a Body, and vice-versa. To put in different terms, these functional restrictions of natural types are sorts of Roles types.

The predicate $\varphi$ to hold for instances of functional restrictions $\mathrm{X}^{\mathrm{F}}$ and $\mathrm{Y}^{\mathrm{F}}$ requires the presence of a relator $r$ to mediate these instances. This requires that the functional qua individuals inhering in the mediated instances of $\mathrm{X}^{\mathrm{F}}$ and $\mathrm{Y}^{\mathrm{F}}$ share a genuine foundation. The formula (1) of generic functional dependence between $\mathrm{X}$ and $\mathrm{Y}$ can then be better expressed as: (2). $\mathrm{GFD}(\mathrm{X}, \mathrm{Y}) \equiv \forall \mathrm{x}(\mathrm{x}: \mathrm{X}) \wedge \mathrm{F}(\mathrm{x}, \mathrm{X}) \rightarrow \exists \mathrm{y}(\mathrm{y}: \mathrm{Y}) \wedge \mathrm{F}(\mathrm{y}, \mathrm{Y}) \wedge$ $\varphi(\mathrm{x}, \mathrm{y})$. Notice that, by definition, a relator must mediate at least two distinct individuals. As a consequence, we have that $\varphi(\mathrm{x}, \mathrm{y})$ implies $\neg(\mathrm{y}=\mathrm{x})$, rendering this condition superfluous in the consequent of formula (2).

Suppose that the universal $\mathrm{X}$ is a specialization of another universal $\mathrm{A}$. Then not only every $X$ is an A but whenever an $X$ functions as such it also functions as an A [2]. For example, suppose that $\mathrm{X}$ and $\mathrm{A}$ are the types MechanicHeart and Heart, respectively. Whenever a MechanicHeart functions as a MechanicHeart, it also functions as a Heart, or alternatively, whenever a MechanicHeart bears the behaviour (or proper- 
ties) of a functioning MechanicHeart, then it also bears the properties of a functioning Heart. This is illustrated in figure 4.a. We thus have that (3). $(\mathrm{F}(\mathrm{x}, \mathrm{X}) \wedge$ Subtype $(\mathrm{X}, \mathrm{Y}))$ $\rightarrow \mathrm{F}(\mathrm{x}, \mathrm{Y})$
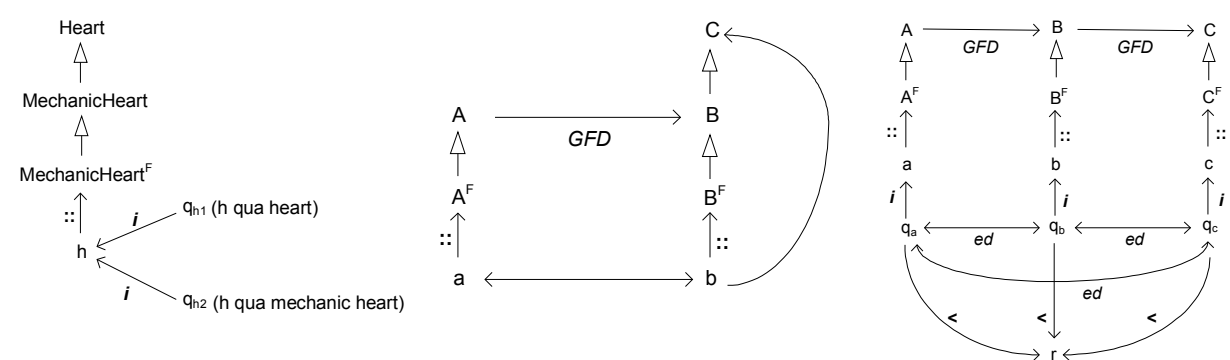

Fig.4.(a-left) Propagation of Functioning to the Supertype. (b-center) Propagation of Functioning to the Supertype. (c-right) Transitivity of General Functional Dependence.

Suppose the situation depicted in figure 4.b. The universal A is generally functionally dependent on universal B. Thus, for every instance $a$ of A that functions as such there is an instance $b$ of $\mathrm{B}$ functioning as a B. Moreover, the predicate $\varphi$ holds for $a$ and $b$. Now, since $\mathrm{b}$ is also a $\mathrm{C}$ and, due to (3), $\mathrm{b}$ also functions as a $\mathrm{C}$. Hence, we have that whenever an instance $a$ of A functions as such there is an instance $\mathrm{b}$ of $\mathrm{C}$ that functions as a C. Since $\varphi(a, b)$, we can derive that $\operatorname{GFD}(A, C)$. Thus, we have that the following is always true: (4). $\operatorname{GFD}(X, Y) \wedge \operatorname{Subtype}(Y, Z) \rightarrow \operatorname{GFD}(X, Z)$.

Now, suppose the situation depicted in figure 4.c. In this model, every instance $a$ of A functioning as an A bears a particular $\mathrm{q}_{\mathrm{a}}$ behaviour. The qua individual $\mathrm{q}_{\mathrm{a}}$ is existentially dependent on the qua individual $\mathrm{q}_{b}$, i.e., on the behaviour of $a b$ functioning as a B. However, this model also represents that if $\mathrm{b}$ functions as a B (bears $\mathrm{q}_{\mathrm{b}}$ ) there is a $\mathrm{c}$ functioning as a $\mathrm{C}$, i.e., bearing a $\mathrm{C}$ behavior $\mathrm{q}_{\mathrm{c}}$. Due to transitivity of existential dependence [4], we have that $\mathrm{q}_{\mathrm{a}}$ is existential dependent also on $\mathrm{q}_{\mathrm{c}}$. Additionally, $\mathrm{q}_{\mathrm{a}}$ and $\mathrm{q}_{\mathrm{b}}$ share the same foundation and so do $\mathrm{q}_{\mathrm{b}}$ and $\mathrm{q}_{\mathrm{c}}$. Thus, $\mathrm{q}_{\mathrm{a}}$ and $\mathrm{q}_{\mathrm{c}}$ also must share the same foundation. In other words, whatever is responsible for creating $\mathrm{q}_{\mathrm{a}}$ and $\mathrm{q}_{\mathrm{b}}$ must also be responsible for creating $\mathrm{q}_{\mathrm{c}}$. By definition, a relator is an aggregation of qua individuals that share the same foundation. We can then define a relator $r$ which consists of $q_{a}, q_{b}$ and $q_{c}$. Consequently, we have that $\varphi(a, b)$, $\varphi(\mathrm{b}, \mathrm{c})$ and $\varphi(\mathrm{a}, \mathrm{c})$. Now, we have that for every instance $a$ of A functioning as an A, there is an instance of $c$ functioning as a $C$. Since $\varphi(a, c)$, we then have that $\operatorname{GFD}(A, C)$. This argument shows that the following is always true: $(5)$. $\operatorname{GFD}(\mathrm{X}, \mathrm{Y}) \wedge$ $\mathrm{GFD}(\mathrm{Y}, \mathrm{Z}) \rightarrow \mathrm{GFD}(\mathrm{X}, \mathrm{Z})$.

Although formula (2) defines the notion of general dependence, we need in addition to establish that a functional dependence link holds precisely between two individual entities $\mathrm{x}$ and $\mathrm{y}:(6) . \operatorname{IFD}(\mathrm{x}, \mathrm{X}, \mathrm{y}, \mathrm{Y}) \equiv \mathrm{GFD}(\mathrm{X}, \mathrm{Y}) \wedge \mathrm{x}:: \mathrm{X} \wedge \mathrm{y}: \mathrm{Y} \wedge(\mathrm{F}(\mathrm{x}, \mathrm{X})$ $\rightarrow \mathrm{F}(\mathrm{y}, \mathrm{Y}))$. This predicate termed individual functional dependence states that if an individual $\mathrm{x}:: \mathrm{X}$ is individually functionally dependent of another individual $\mathrm{y}:: \mathrm{Y}$ in a given situation then: (i) there is a generic functional dependence between their types; (ii) $\mathrm{x}$ and $\mathrm{y}$ are classified as those given types in that situation; (iii) for $\mathrm{x}$ to function as a $\mathrm{X}$ in that situation, then $\mathrm{y}$ must function as a $\mathrm{Y}$. 
An example of individual functional dependence is one between a particular heart $h$ and a particular body $\mathrm{b}$ in figure 2 . As discussed, there is a generic functional dependence between the types Heart and Body, and if in a given circumstance a heart $h$ functions as a heart there is a body $b$ that functions as a body in that circumstance.

\section{A typology of Functional Part-Whole Relations and Visual Patterns for Isolating the Scope of Transitivity}

Let us now return to the example of figure 2 of a parthood relation between the universals Heart and Body. In this model, a particular heart $\mathrm{h}$ is not only functionally dependent of $a$ body $b$ in a given situation, but $h$ is also part of $b$. This type of the parthood relation is termed in [2] direct functional parthood of type 1:

Definition 1 (Direct Functional Part of type 1): An individual $x$ instance of $X$ is a direct functional part of type 1 of an individual $y$ of type $Y$ (symbolized as $\left.\mathrm{d}_{1}(\mathrm{x}, \mathrm{X}, \mathrm{y}, \mathrm{Y})\right)$ iff $\mathrm{x}$ is a part of $\mathrm{y}$ and $\mathrm{x}$ is individually functionally dependent of $\mathrm{y}$. Formally, $\mathrm{d}_{1}(\mathrm{x}, \mathrm{X}, \mathrm{y}, \mathrm{Y}) \equiv((\mathrm{x}<\mathrm{y}) \wedge \operatorname{IFD}(\mathrm{x}, \mathrm{X}, \mathrm{y}, \mathrm{Y}))$.

Examples of $\mathrm{d}_{1}$ include cuff-sleeve, stem-plant, carburetor-engine, finger-hand, handarm, arm-body, hand-body, heart-body, heart-circulatory system. In conformance with the findings of [3], we propose that a parthood relation between two functional complexes (such as the one depicted in figure 2) should be interpreted as a case of direct functional parthood. In this specific case, the model implies that: $\forall \mathrm{x}$ x::Heart $\rightarrow \exists \mathrm{y}$ $\mathrm{y}:$ Body $\wedge \mathrm{d}_{1}(\mathrm{x}$, Heart, $\mathrm{y}$, Body $\left.)\right)$ ).

Now, suppose that we have a model such as the one represented of figure 5.a.

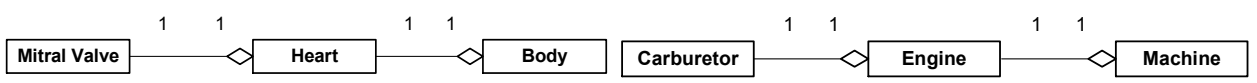

Fig.5.(a-left) Examples of direct functional part of type 1. (b) Examples of direct functional part of type 1: transitivity always hold across parthood relations of this type.

In this case, both the relationships between Heart and Body, and between Mitral Valve and Heart, are mapped in the instance level to cases of direct functional parthood(1), i.e., (i) $\forall \mathrm{x} x::$ Heart $\rightarrow \exists \mathrm{y}$ y::Body $\wedge \mathrm{d}_{1}(\mathrm{x}$, Heart,y,Body); (ii) $\forall \mathrm{x}$ $\mathrm{x}::$ MitralValve $\rightarrow \exists \mathrm{y}$ y::Heart $\wedge \mathrm{d}_{1}(\mathrm{x}$, MitralValve, $\mathrm{y}$, Heart $)$. The important question at this point is: from (i) and (ii), can we derive formula (iii) $\forall \mathrm{x}$ x::MitralValve $\rightarrow \exists \mathrm{y}$ $y:$ Body $\wedge d_{1}\left(x\right.$, MitralValve,y, Body). Notice that (iii) follows from (i) and (ii) iff $d_{1}$ is transitive. Thus, the this question can be rephrased as: is direct functional parthood(1) a transitive relation?

In the sequel we demonstrate that this is indeed the case. The abbreviations in the proofs are: (a) TFP (transitivity of formal parthood); (b) TLI (transitivity of the logical implication); (c) EC (Elimination of the Disjunction), and (d) IC (Introduction of the Disjunction).

(T1) Theorem 1: $d_{1}(x, X, y, Y) \wedge d_{1}(y, Y, z, Z) \rightarrow d_{1}(x, X, z, Z)$

Proof:

1. $\mathrm{d}_{1}(\mathrm{x}, \mathrm{X}, \mathrm{y}, \mathrm{Y})$

2. $\mathrm{d}_{1}(\mathrm{y}, \mathrm{Y}, \mathrm{z}, \mathrm{Z})$ 


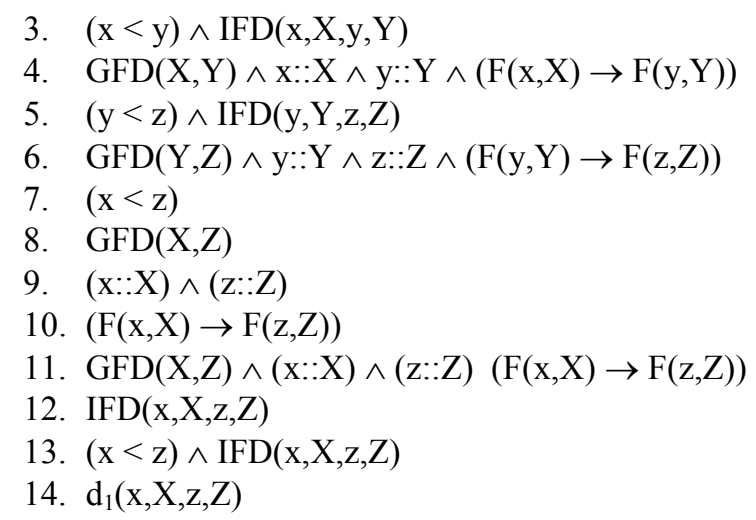

1, Definition 1

$3,(6)$

2, Definition 1

$5,(6)$

3,5 , TFP

$4,6,(5)$

$4,6, \mathrm{EC}$

4,6, TLI

$8,9,10$, IC

$11,(6)$

7,12, IC

13, Definition 1

We can generalize this result for any chain of direct functional dependence in a model. Another example of such case is depicted in figure 5.b.

In models such as 5.a-b, the parthood relation represents functional dependence in both directions. Take for instance figure 5.b. The minimum cardinality constraint of 1 in the Engine association end of the aggregation relation between Carburator and Engine implies that every instance of Carburator necessitates an Engine to function as a Carburator. Likewise, the minimum cardinality constraint of 1 in the Carburator association end of that relation implies that every Engine necessitates a Carburator to function as an Engine. [2] names this type of functional parthood in which $x$ is part of $y$ but $y$ as $Y$ is individually functionally dependent on $x$ as an $X$ direct functional part$\operatorname{hood}(2)$ :

Definition 2 (Direct Functional Part of type 2): An individual $x$ instance of $X$ is a direct functional part of type 2 of an individual $\mathrm{y}$ of type $\mathrm{Y}$ (symbolized as $\left.\mathrm{d}_{2}(\mathrm{x}, \mathrm{X}, \mathrm{y}, \mathrm{Y})\right)$ iff $\mathrm{x}$ is a part of $\mathrm{y}$ and $\mathrm{y}$ is individually functionally dependent of $\mathrm{x}$. Formally, $\mathrm{d}_{2}(\mathrm{x}, \mathrm{X}, \mathrm{y}, \mathrm{Y}) \equiv(\mathrm{x}<\mathrm{y}) \wedge \operatorname{IFD}(\mathrm{y}, \mathrm{Y}, \mathrm{x}, \mathrm{X})$.

Examples of $\mathrm{d}_{2}$ include wall-house, engine-car, electron-atom, atom-molecule, fingerhand, hand-arm, cell-heart, feather-canary. In the sequel, we prove that $\mathrm{d}_{2}$ is also transitive.

(T2) Theorem 2: $d_{2}(x, X, y, Y) \wedge d_{2}(y, Y, z, Z) \rightarrow d_{2}(x, X, z, Z)$

\section{Proof:}

(1). $\mathrm{d}_{2}(\mathrm{x}, \mathrm{X}, \mathrm{y}, \mathrm{Y}) \quad \mathrm{T} 2$

(2). $\mathrm{d}_{2}(\mathrm{y}, \mathrm{Y}, \mathrm{z}, \mathrm{Z}) \quad \mathrm{T} 2$

(3). $(\mathrm{x}<\mathrm{y}) \wedge \operatorname{IFD}(\mathrm{y}, \mathrm{Y}, \mathrm{x}, \mathrm{X}) \quad$ 1, Definition 2

(4). GFD(Y,X) $\wedge \mathrm{y}:: \mathrm{Y} \wedge \mathrm{x}:: \mathrm{X} \wedge(\mathrm{F}(\mathrm{y}, \mathrm{Y}) \rightarrow \mathrm{F}(\mathrm{x}, \mathrm{X}))$

(5). $(\mathrm{y}<\mathrm{z}) \wedge \operatorname{IFD}(\mathrm{z}, \mathrm{Z}, \mathrm{y}, \mathrm{Y}) \quad$ 2, Definition 2

(6). $\mathrm{GFD}(\mathrm{Z}, \mathrm{Y}) \wedge \mathrm{z}:: \mathrm{Z} \wedge \mathrm{y}:: \mathrm{Y} \wedge(\mathrm{F}(\mathrm{z}, \mathrm{Z}) \rightarrow \mathrm{F}(\mathrm{y}, \mathrm{Y}))$

(7). $(\mathrm{x}<\mathrm{z}) \quad 3,5$, TFP

(8). GFD(Z,X) 4,6, (5)

(9). $(\mathrm{z}:: Z) \wedge(\mathrm{x}:: \mathrm{X}) \quad 4,6, \mathrm{EC}$

(10). (F(z,Z) $\rightarrow \mathrm{F}(\mathrm{x}, \mathrm{X})) \quad$ 4,6, TLI

(11). $\mathrm{GFD}(\mathrm{Z}, \mathrm{X}) \wedge(\mathrm{z}: \mathrm{Z}) \wedge(\mathrm{x}:: \mathrm{X})(\mathrm{F}(\mathrm{z}, \mathrm{Z}) \rightarrow \mathrm{F}(\mathrm{x}, \mathrm{X})) \quad 8,9,10, \mathrm{IC}$ 
(12). $\operatorname{IFD}(\mathrm{z}, \mathrm{Z}, \mathrm{x}, \mathrm{X})$

(13). $\quad(x<z) \wedge \operatorname{IFD}(z, Z, x, X)$

Whenever in a conceptual model we have a representation of a parthood relation between complex objects such as in figures 5 .a-b, we have both a case of $d_{1}$ and a case of $\mathrm{d}_{2}$. In particular, the model of figure 5.b implies both the formulae: (i) $\forall \mathrm{x}$ $\mathrm{x}::$ Carburator $\rightarrow \exists \mathrm{y}$ y::Engine $\wedge \mathrm{d}_{1}(\mathrm{x}$, Carburator, $\mathrm{y}$, Engine) and (ii) $\forall \mathrm{x}$ x:: Engine $\rightarrow$ $\exists y$ y:: Carburator $\wedge d_{2}(y$, Carburator, $x$,Engine $)$. Since both $d_{1}$ and $d_{2}$ are transitive, we maintain that transitivity holds within any chain of direct functional dependence relations in a conceptual model.

Now, take for instance the relationship depicted in figure 6 below.

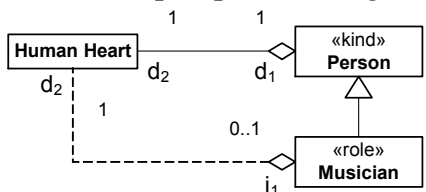

Fig.6. Example of indirect functional part of type 1(from Human Heart to Musician).

Every human heart necessitates a person, and every person necessitates a human heart, i.e., both $\mathrm{d}_{1}$ and $\mathrm{d}_{2}$ hold between direct instances of human heart and person. Moreover, every musician is a person. So, as any person, a musician necessitates a human heart, i.e., $\mathrm{d}_{2}$ holds also between instances of human heart and musician. However, it is not the case that a direct functional dependence holds between human heart and musician. A human heart necessitates a person, but this person does not have to be a musician (this is made evident by the cardinality $0 . .1$ of the inherited relation between these two universals). This type of relationship is termed indirect functional parthood (1) in [2] and it is defined as follows:

Definition 3 (Indirect Functional Part of type 1): $i_{1}(x, X, y, Y) \equiv(x<y) \wedge$ $\operatorname{IIFD}(\mathrm{x}, \mathrm{X}, \mathrm{y}, \mathrm{Y})$. IIFD(x,X,y,Y) is the relation of individual indirect functional dependence and is defined as (7). $\operatorname{IIFD}(\mathrm{x}, \mathrm{X}, \mathrm{y}, \mathrm{Y}) \equiv \mathrm{y}:: \mathrm{Y} \wedge \exists \mathrm{Z}$ (Subtype $(\mathrm{Y}, \mathrm{Z}) \wedge$ $\operatorname{IFD}(\mathrm{x}, \mathrm{X}, \mathrm{y}, \mathrm{Z}))$.

To put it in a simple way, $\mathrm{x}$ as an $\mathrm{X}$ is individually indirect functional dependent of $\mathrm{y}$ as a $\mathrm{Y}$ iff for $\mathrm{x}$ to function as an $\mathrm{X}$, $\mathrm{y}$ must function as a $\mathrm{Z}$, whereas $\mathrm{Z}$ is a more general universal (subsuming that $Y$ ) that $y$ instantiates. Examples of $i_{1}$ include handledoor (with "movable entity" for type subsuming "door"), door-house (with "wall, enclosure or building" subsuming "house"), engine-car (with "machine" subsuming "car"), brick-wall (with "construction" subsuming "wall”), valve-carburetor (with "fluid-holding device" subsuming carburetor), cell-heart (with "organ" subsuming "heart"), feather-canary (with "bird" subsuming "canary").

Now, take the model depicted in figure 7 below. There are two potential parthood relations $\mathbf{A}$ and B. The relation A between Mitral Valve and Musician holds iff transitivity holds across (Mitral Valve $\stackrel{d 1}{\longrightarrow}$ Human Heart) and (Human Heart $\stackrel{i 1}{\longrightarrow}$ Musician), since in the other reading of these relations, i.e., (Mitral 
Valve $\stackrel{d 2}{\longrightarrow}$ Human Heart) and (Human Heart $\stackrel{d 1}{\longrightarrow}$ Musician), transitivity is already guaranteed by theorem (T2). To put it baldly, relation $\mathbf{A}$ is transitive in this case iff $\mathbf{d}_{\mathbf{1}}(\mathbf{x}, \mathbf{X}, \mathbf{y}, \mathbf{Y}) \wedge \mathbf{i}_{\mathbf{1}}(\mathbf{y}, \mathbf{Y}, \mathbf{z}, \mathbf{Z}) \rightarrow \mathbf{i}_{\mathbf{1}}(\mathbf{x}, \mathbf{X}, \mathbf{z}, \mathbf{Z})$ is a theorem. Likewise, relation $\mathbf{B}$ is transitive in this case iff $\mathbf{i}_{\mathbf{1}}(\mathbf{x}, \mathbf{X}, \mathbf{y}, \mathbf{Y}) \wedge \mathbf{d}_{\mathbf{1}}(\mathbf{y}, \mathbf{Y}, \mathbf{Z}, \mathbf{Z}) \rightarrow \mathbf{i}_{\mathbf{1}}(\mathbf{x}, \mathbf{X}, \mathbf{z}, \mathbf{Z})$ is a theorem. As we show in the sequel, $\mathbf{d}_{\mathbf{1}}(\mathbf{x}, \mathbf{X}, \mathbf{y}, \mathbf{Y}) \wedge \mathbf{i}_{\mathbf{1}}(\mathbf{y}, \mathbf{Y}, \mathbf{z}, \mathbf{Z}) \rightarrow \mathbf{d}_{\mathbf{1}}(\mathbf{x}, \mathbf{X}, \mathbf{z}, \mathbf{Z}) \vee \mathbf{i}_{\mathbf{1}}(\mathbf{x}, \mathbf{X}, \mathbf{z}, \mathbf{Z})$ is a theorem (T3) while $\mathbf{i}_{1}(\mathbf{x}, \mathbf{X}, \mathbf{y}, \mathbf{Y}) \wedge \mathbf{d}_{1}(\mathbf{y}, \mathbf{Y}, \mathbf{z}, \mathbf{Z}) \rightarrow \mathbf{d}_{\mathbf{1}}(\mathbf{x}, \mathbf{X}, \mathbf{z}, \mathbf{Z}) \vee \mathbf{i}_{\mathbf{1}}(\mathbf{x}, \mathbf{X}, \mathbf{z}, \mathbf{Z})$ is not. Therefore, whilst $\mathbf{A}$ is a case of indirect functional parthood between Mitral Valve and $\mathbf{M u}-$ sician, relation $\mathbf{B}$ is not warranted and, hence, must not exist in figure 7.

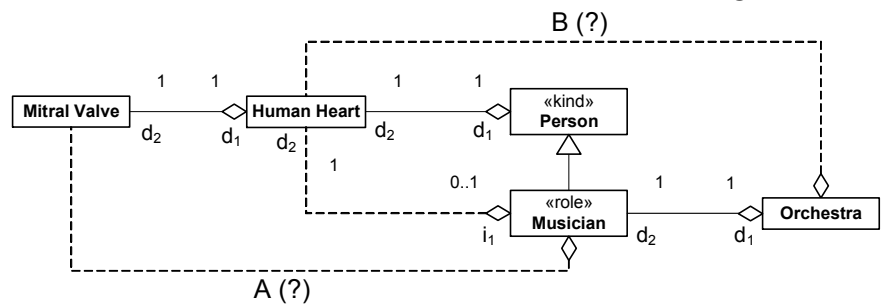

Fig.7. Two candidate parthood relations due to transitivity.

(T3) Theorem 3: $d_{1}(x, X, y, Y) \wedge i_{1}(y, Y, z, Z) \rightarrow i_{1}(x, X, z, Z)$

Proof:

(1). $d_{1}(x, X, y, Y)$

(2). $\mathrm{i}_{1}(\mathrm{y}, \mathrm{Y}, \mathrm{z}, \mathrm{Z})$

(3). $(\mathrm{x}<\mathrm{y}) \wedge \operatorname{IFD}(\mathrm{x}, \mathrm{X}, \mathrm{y}, \mathrm{Y}) \quad$ 1, Definition 1

(4). $\operatorname{GFD}(X, Y) \wedge x:: X \wedge y:: Y \wedge(F(x, X) \rightarrow F(y, Y)) \quad 3,(6)$

(5). $(\mathrm{y}<\mathrm{z}) \wedge \operatorname{IIFD}(\mathrm{y}, \mathrm{Y}, \mathrm{z}, \mathrm{Z}) \quad$ 2, Definition 3

(6). $\mathrm{z}:: \mathrm{Z} \wedge \exists \mathrm{W}(\operatorname{Subtype}(\mathrm{Z}, \mathrm{W}) \wedge \mathrm{IFD}(\mathrm{y}, \mathrm{Y}, \mathrm{z}, \mathrm{W}))$

(7). $\mathrm{GFD}(\mathrm{Y}, \mathrm{W}) \wedge \mathrm{y}:: \mathrm{Y} \wedge \mathrm{z}: \mathrm{W} \wedge(\mathrm{F}(\mathrm{y}, \mathrm{Y}) \rightarrow \mathrm{F}(\mathrm{z}, \mathrm{W})) \quad 6,(6)$

(8). $(\mathrm{x}<\mathrm{z}) \quad 3,5, \mathrm{TFP}$

(9). $\operatorname{GFD}(\mathrm{X}, \mathrm{W}) \quad 4,7,(5)$

(10). $(\mathrm{x}:: \mathrm{X}) \wedge(\mathrm{z}:: \mathrm{W}) \quad 4,7, \mathrm{EC}$

(11). (F(x,X) $\rightarrow \mathrm{F}(\mathrm{z}, \mathrm{W})) \quad$ 4,7,TLI

(12). $\mathrm{GFD}(\mathrm{X}, \mathrm{W}) \wedge(\mathrm{x}: \mathrm{X}) \wedge(\mathrm{z}:: \mathrm{W})(\mathrm{F}(\mathrm{x}, \mathrm{X}) \rightarrow \mathrm{F}(\mathrm{z}, \mathrm{W})) \quad 9,10,11, \mathrm{IC}$

(13). $\operatorname{IFD}(\mathrm{x}, \mathrm{X}, \mathrm{z}, \mathrm{W}) \quad 12,(6)$

(14). $\mathrm{z}:: \mathrm{Z} \wedge \exists \mathrm{W}(\operatorname{Subtype}(\mathrm{Z}, \mathrm{W}) \wedge \mathrm{IFD}(\mathrm{x}, \mathrm{X}, \mathrm{z}, \mathrm{W})$

(15). $\operatorname{IIFD}(x, X, z, Z) \quad 14,(7)$

(16). $(\mathrm{x}<\mathrm{z}) \wedge \operatorname{IIFD}(\mathrm{x}, \mathrm{X}, \mathrm{z}, \mathrm{Z}) \quad 8,15$, IC

(17). $i_{1}(x, X, z, Z) \quad 16$, Definition 3

Let us now modify the model of figure 7 to depict a more realistic conceptualization. In this modified specification (figure 8) we have that every Blood Pump is part of a Circulatory System and necessitates a Circulatory System in order to work as such $\left(d_{1}\right)$. Likewise, every Circulatory System has as part a Blood Pump and necessitates the latter to work as such $\left(\mathrm{d}_{2}\right)$. As any Blood Pump, a Biological Heart is part of a Circulatory System and necessitates a Circulatory System to work as such, i.e., direct functional dependence (2) is inherited by Biological Heart from the subsuming universal. The same obviously holds for Artificial Heart. However, it is not the case that 
a Circulatory System is directly functionally dependent of a Biological Heart specifically. To put it in an alternative way, a Circulatory System, in order to function as such, relies on the behavior of a Blood Pump, but this behavior does not have to be afforded in the specific way a Biological Heart does. In [2], this type of relationship between Biological Heart and Circulatory System is termed indirect functional parthood (2) and it is defined as follows:

Definition 4 (Indirect Functional Part of type 2): $i_{2}(x, X, y, Y) \equiv(x<y) \wedge$ $\operatorname{IIFD}(\mathrm{y}, \mathrm{Y}, \mathrm{x}, \mathrm{X})$.

Examples of $i_{2}$ include heart-circulatory system (with "blood pump" subsuming "heart"), brick-wall (with "construction material" subsuming "brick").

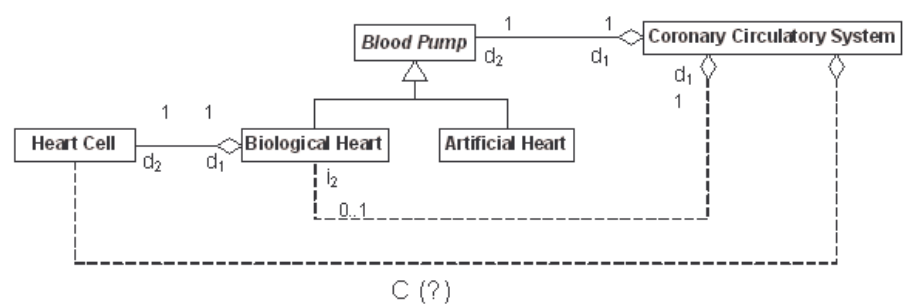

Fig.8. Example of an indirect functional parthood of type 2 (from Biological Heart to Coronary Circulatory System ) and of a candidate parthood relationship (C) due to transitivity.

Once more, we have the question: does transitivity hold across (Heart Cell $\stackrel{d 2}{\longrightarrow}$ Biological Heart) and (Biological Heart $\stackrel{i 2}{\longrightarrow}$ Coronary Circulatory System)? In the other reading we have (Heart Cell Valve $\stackrel{d 1}{\longrightarrow}$ Biological Heart) and (Biological Heart $\stackrel{d 1}{\longrightarrow}$ Coronary Circulatory System), thus, relation C is warranted iff the question above is answered affirmatively. The answer in this case is negative, since $\mathbf{d}_{\mathbf{2}}(\mathbf{x}, \mathbf{X}, \mathbf{y}, \mathbf{Y}) \wedge \mathbf{i}_{\mathbf{2}}(\mathbf{y}, \mathbf{Y}, \mathbf{z}, \mathbf{Z}) \rightarrow \mathbf{d}_{\mathbf{2}}(\mathbf{x}, \mathbf{X}, \mathbf{z}, \mathbf{Z}) \vee \mathbf{i}_{\mathbf{2}}(\mathbf{x}, \mathbf{X}, \mathbf{z}, \mathbf{Z})$ cannot be shown to be a theorem in this theory. However, the following is a theorem:

(T4) Theorem 4: $\mathbf{i}_{2}(x, X, y, Y) \wedge d_{2}(y, Y, z, Z) \rightarrow i_{2}(x, X, z, Z)$

Proof:

$\begin{array}{lll}\text { (15). } & \mathrm{i}_{2}(\mathrm{x}, \mathrm{X}, \mathrm{y}, \mathrm{Y}) & \mathrm{T} 4\end{array}$

(16). $\quad \mathrm{d}_{2}(\mathrm{y}, \mathrm{Y}, \mathrm{z}, \mathrm{Z}) \quad \mathrm{T} 4$

(17). $\quad(\mathrm{x}<\mathrm{y}) \wedge \operatorname{IIFD}(\mathrm{y}, \mathrm{Y}, \mathrm{x}, \mathrm{X}) \quad 1$, Definition 4

(18). $\quad(\mathrm{y}<\mathrm{z}) \wedge \operatorname{IFD}(\mathrm{z}, \mathrm{Z}, \mathrm{y}, \mathrm{Y}) \quad 2$, Definition 2

(19). $\quad \mathrm{x}:: \mathrm{X} \wedge \exists \mathrm{W}(\operatorname{Subtype}(\mathrm{X}, \mathrm{W}) \wedge \operatorname{IFD}(\mathrm{y}, \mathrm{Y}, \mathrm{x}, \mathrm{W}))$

(20). $\quad \mathrm{GFD}(\mathrm{Y}, \mathrm{W}) \wedge \mathrm{y}:: \mathrm{Y} \wedge \mathrm{x}:: \mathrm{W} \wedge(\mathrm{F}(\mathrm{y}, \mathrm{Y}) \rightarrow \mathrm{F}(\mathrm{x}, \mathrm{W})) \quad 5,(6)$

(21). $\quad \mathrm{GFD}(\mathrm{Z}, \mathrm{Y}) \wedge \mathrm{z}:: \mathrm{Z} \wedge \mathrm{y}:: \mathrm{Y} \wedge(\mathrm{F}(\mathrm{z}, \mathrm{Z}) \rightarrow \mathrm{F}(\mathrm{y}, \mathrm{Y}))$

(22). $(\mathrm{x}<\mathrm{z}) \quad 3,4, \mathrm{TFP}$

(23). $\operatorname{GFD}(\mathrm{Z}, \mathrm{W}) \quad 6,7,(5)$

(24). $\quad(\mathrm{z}:: \mathrm{Z}) \wedge(\mathrm{x}:: \mathrm{W}) \quad 6,7, \mathrm{EC}$

(25). $\quad(\mathrm{F}(\mathrm{z}, \mathrm{Z}) \rightarrow \mathrm{F}(\mathrm{x}, \mathrm{W})) \quad 6,7, \mathrm{TLI}$

(26). $\quad \mathrm{GFD}(\mathrm{Z}, \mathrm{W}) \wedge(\mathrm{z}:: \mathrm{Z}) \wedge(\mathrm{x}:: \mathrm{W})(\mathrm{F}(\mathrm{z}, \mathrm{Z}) \rightarrow \mathrm{F}(\mathrm{x}, \mathrm{W})) \quad 9,10,11, \mathrm{IC}$

(27). $\operatorname{IFD}(\mathrm{z}, \mathrm{Z}, \mathrm{x}, \mathrm{W}) \quad 12,(6)$

(28). $\quad \mathrm{x}:: \mathrm{X} \wedge \exists \mathrm{W}(\operatorname{Subtype}(\mathrm{X}, \mathrm{W}) \wedge \operatorname{IFD}(\mathrm{z}, \mathrm{Z}, \mathrm{x}, \mathrm{W}) \quad$ 5,13,IC 
Due to this theorem we have that the relation D between Biological Heart and Circulatory System (depicted in figure 8 below) is warranted, since transitivity holds across (Biological Heart $\stackrel{i 2}{\longrightarrow}$ Coronary Circulatory System) and (Coronary Circulatory System $\stackrel{d 2}{\longrightarrow}$ Circulatory System) in this case.

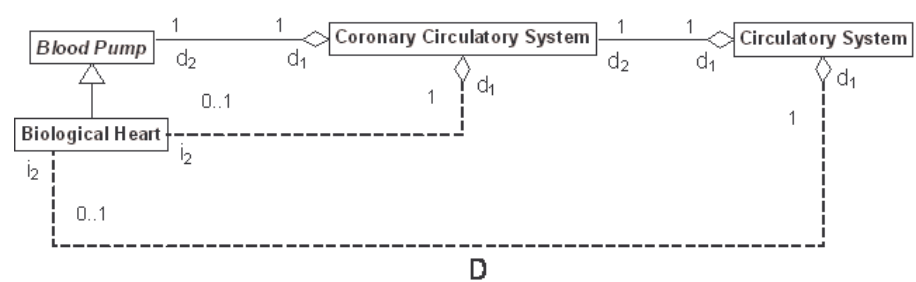

Fig.8. Example of an indirect functional parthood of type 2 due to transitivity (from Biological Heart to Circulatory System).

We conclude this section by providing the following set of visual patterns that can isolate the scope of transitivity in conceptual models containing parthood relations between functional complexes (functional parthood). Transitivity can be guaranteed for these relations only in cases where the patterns of figures (9.a-c) occur. In summary, parthood relations between concrete functional complexes are neither transitive nor intransitive, but non-transitive relation (i.e., transitive in certain cases and intransitive in others). One of the main contributions of this paper is to provide a systematic engineering tool based on a solid theory to exactly inform the modeler which are the cases in which transitivity hold.

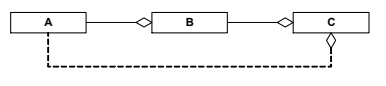

(a)

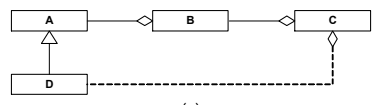

(c)

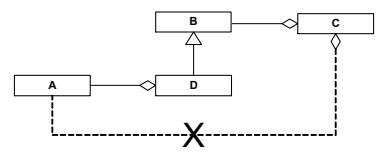

(e)

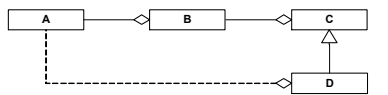

(b)

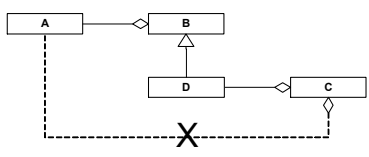

(d)

Fig.9. The patterns of figures (a-c) represent cases in which a derived functional transitive parthood relation can be inferred. Instransitive cases are shown in figures (d) and (e).

\section{$5 \quad$ Final Considerations}

The work presented here is part of a series of publications (e.g., $[4,6,8])$ in which we make use of Ontological theories for analyzing, re-designing and providing real-world semantics for conceptual modeling languages and models. Here we build on a formal 
theory of linguistic functional parthood presented in [2], and on and ontological theory of relationships presented [8] to provide a solution to one classical problem in conceptual modeling, namely, deciding on the transitivity of part-whole relations between the most common objects in conceptual models (functional complexes).

Despite being precise and ontologically well-founded, the theory presented here is of a substantial complexity, thus, demanding for its full understanding at least a basic notion of logics and an advanced understanding of formal ontology. For this reason, and with the intent to provide some methodological tools for helping the modeler in employing the results of this theory, we proposed a number of visual patterns that can be directly applied to diagrams to isolate the scope of transitivity of functional partwhole relations. We believe that these results contribute to the task of defining sound engineering tools and principles for the practice of conceptual modeling. It is important to emphasize that these patterns can be used to isolate the contexts of transitivity in a diagram regardless of the content of what is being represented there. As a consequence, fully automated tool support can be built for this task in a relatively simple way, since the underlying algorithm merely has to check structural properties of the diagram and not the content of involved nodes. We are currently working on the implementation of prototype to do exactly that.

Acknowledgement. This work is partly funded by the Infra-Modela (FAPES) project.

\section{References}

1. Winston M.E.; Chaffin R.; Herrman D. A taxonomy of part-whole relations, Cognitive Science 11, pp.417-444, 1987.

2. Vieu, L.; Aurnague, M. Part-of Relations, Functionality and Dependence, In: M. Aurnague, M. Hickmann \& L. Vieu (eds.), Categorization of Spatial Entities in Language and Cognition. Amsterdam: John Benjamins, 2007.

3. Keet, M. Artale, A. Representing and Reasoning over a Taxonomy of Part-Whole Relations. Applied Ontology, Vol.3: 1-2, pp.91-110, IOS Press, 2008.

4. Guizzardi, G., Ontological Foundations for Structural Conceptual Models, PhD Thesis, University of Twente, The Netherlands, 2005.

5. Gerstl, P. and Pribbenow, S., Midwinters, End Games, and Bodyparts. A Classification of Part-Whole Relations, Intl. Journal of Human-Computer Studies 43: 865-889, 1995.

6. Guizzardi, G., Herre, H., Wagner G. Towards Ontological Foundations for UML Conceptual Models. $1^{\text {st }}$ Intenational Conference on Ontologies, Databases and Applications of Semantics (ODBASE), LNCS 2519, Springer-Verlag, 2002.

7. Opdahl A., Henderson-Sellers, B., Barbier F. Ontological Analysis of whole-part relationships in OO-models, Information and Software Technology 43, pp. 387-399, 2001.

8. Guizzardi, G., Wagner, G. What's in a Relationship: An Ontological Analysis, $27^{\text {th }}$ Intl. Conf. on Conceptual Modeling (ER), Barcelona, LNCS 5231, Springer-Verlag, 2008.

9. Heller, B., Herre, H. Ontological Categories in GOL, Axiomathes 14: 71-90 Kluwer Academic Publishers, 2004.

10. Thomasson, A.L. Ontological Categories and How to Use Them, The Electronic Journal of Analytic Philosophy, Indiana University, USA, Issue 5, Spring, 1997.

11. Wieringa, R.J. de Jonge, W., Spruit, P.A. Using dynamic classes and role classes to model object migration.. Theory and Practice of Object Systems, 1(1), 61-83, 1995.

12. Steimann, F.: .On the representation of roles in object-oriented and conceptual modeling.. Data \& Knowledge Engineering 35:1, 2000. 